\title{
Histórico genético e populacional do rebanho Nelore Puro de Origem no Sertão Nordestino
}

\author{
Carlos Henrique Mendes Malhado(1), Paulo Luiz Souza Carneiro(1), Raimundo Martins Filho(2) \\ e Danielle Maria Machado Ribeiro Azevedo(3)
}

\begin{abstract}
(1)Universidade Estadual do Sudoeste da Bahia, Departamento de Ciências Biológicas, Avenida José Moreira Sobrinho, s/no, Jequiezinho, CEP 45200-000 Jequié, BA. E-mail: carlosmalhado@gmail.com, plscarneiro@gmail.com (2)Universidade Estadual do Ceará, Faculdade de Veterinária, Avenida Paranjana, no 1700, Campus do Itaperi, CEP 60740-000 Fortaleza, CE. E-mail: rmartinsfilho@yahoo.com.br ${ }^{(3)} E m b r a p a$ Meio-Norte, BR 343, Km 35, Zona Rural, CEP 64200-970 Parnaíba, PI. E-mail: azevedo@cpamn.embrapa.br
\end{abstract}

Resumo - O objetivo deste trabalho foi avaliar o histórico do rebanho Nelore Puro de Origem no Sertão Nordestino por meio da determinação de sua estrutura populacional e da quantificação do progresso genético, fenotípico e ambiental ocorrido em características de desenvolvimento ponderal. Foram utilizadas informações de pedigree de animais nascidos no período de 1964 a 2006 e dados das massas corporais ajustadas aos 205 e 365 dias de idade de bovinos nascidos de 1978 a 2006. O pequeno número de ancestrais explicou a baixa variabilidade genética e os reduzidos valores dos coeficientes de herdabilidade observados para as características de crescimento. O coeficiente de endogamia média e a percentagem de animais endogâmicos na população aumentaram no decorrer das gerações. Contudo, o coeficiente de endogamia médio dos animais endogâmicos diminuiu, o que é indicativo de que os acasalamentos entre parentes próximos estão sendo evitados. $\mathrm{O}$ tamanho efetivo da população oscilou de 100 a 200 animais em quase todo o período estudado. Não se constatou ganho genético no período. Contudo, a raça obteve um considerável ganho fenotípico ocasionado por melhorias ambientais.

Termos para indexação: endogamia, ganho genético, herdabilidade, intervalo de gerações, pedigree, tamanho efetivo.

\section{Genetic and populational background of Pure Nelore cattle breed in Brazilian Northeastern Sertão}

\begin{abstract}
The objective of this study was to evaluate the Pure Nelore cattle breed background in the Brazilian Northeastern Sertão region by determining its population structure and quantifying genetic, phenotypic and environmental progress based on ponderal development traits. Pedigree data of animals born between 1964 and 2006 and weight values, adjusted to 205 and 365 days of age, of bovines born between 1978 and 2006 were used. The small number of ancestors explained the population's low genetic variability and the reduced heritability coefficient values observed for growth traits. The mean inbreeding coefficient and the percentage of endogamic animals within the population increased over the generations. However, the mean inbreeding coefficient of endogamic animals decreased over the generations, indicating that mating between closely related individuals is being avoided. The effective size of the population ranged from 100 to 200 animals throughout nearly all of the studied period. No genetic gains were detected for this period. Nevertheless, a remarkable phenotypic gain was obtained due to environmental improvements.
\end{abstract}

Index terms: endogamy, genetic gain, heritability, generation interval, pedigree, effective size.

\section{Introdução}

O Sertão Nordestino abrange os estados do Piauí, Bahia, Pernambuco, Rio Grande do Norte, Paraíba e uma pequena área de Alagoas e Sergipe. De acordo com Arruda \& Sugai (1994), o Sertão Nordestino é constituído por 15 microrregiões homogêneas: Floriano, Alto Paranaíba Piauiense, Médio Gurgueia, Alto Piauí e Canindé, Chapadas do Extremo Sul Piauiense, Araripina, Sertão Pernambucano do São Francisco,
Baixo Médio São Francisco, Senhor do Bonfim, Corredeiras do São Francisco, Sertão de Canudos e Sertão de Paulo Afonso. É o espaço menos povoado do Nordeste brasileiro (Arruda \& Sugai, 1994).

A precipitação média nessa região, em torno de 500 a $750 \mathrm{~mm}$ anuais, além de bastante irregular entre os anos, tem uma concentração de mais de $50 \%$ nos meses de fevereiro e março, com um período seco que varia de seis meses no sul do Piauí a dez meses no norte da Bahia. Essa baixa precipitação, somada à sua 
irregularidade, caracteriza a região como sendo de alto risco para atividades agropastoris (Arruda \& Sugai, 1994).

O estudo da estrutura das populações por meio de informações de pedigree pode esclarecer importantes circunstâncias que afetam o seu histórico genético (Valera et al., 2005). Adicionalmente, alguns parâmetros populacionais largamente dependentes do manejo e dos sistemas de acasalamento têm grande impacto na variabilidade genética dos rebanhos Nelore (Malhado et al., 2008). Informações de pedigree são ferramentas importantes em estudos populacionais e têm como vantagem o baixo custo e a simplicidade de obtenção, quando comparadas ao uso de marcadores moleculares.

De acordo com Euclides Filho et al. (2000), o conhecimento da evolução genética de uma população tem importância não só para proceder aos ajustes que se fizerem necessários no direcionamento da seleção, mas também para avaliar o resultado do programa de seleção que vem sendo adotado. Segundo Malhado et al. (2008), a inter-relação da estrutura populacional com progresso genético pode servir para nortear ações futuras, que permitirão o desenvolvimento de estratégias para o progresso genético de uma raça em determinada região.

O estudo conjunto da estrutura populacional por meio de informações de pedigree e de progresso genético é uma importante ferramenta para entender o histórico do melhoramento da raça Nelore no Sertão Nordestino, e servirá para fornecer subsídios para programas de seleção, conservação e expansão da raça na região.

O objetivo deste trabalho foi avaliar o histórico do rebanho Nelore Puro de Origem (PO) no Sertão Nordestino, por meio da determinação de sua estrutura populacional e da quantificação do progresso genético, fenotípico e ambiental em características de desenvolvimento ponderal ocorrido nessa região ao longo de 42 anos.

\section{Material e Métodos}

Os dados utilizados foram provenientes do controle de desenvolvimento ponderal da raça Nelore realizado pela Associação Brasileira dos Criadores de Zebu. Foram utilizadas informações de pedigree de bovinos nascidos no período de 1964 a 2006 e dados das massas corporais ajustadas aos 205 (P205, 3.506 pesagens) e 365 (P365, 2.059 pesagens) dias de idade, de animais nascidos de 1978 a 2006, no Sertão Nordestino, totalizando 5.080 animais na matriz de parentesco.

Para obter as estimativas das variâncias e dos valores genéticos, foi empregada a metodologia da máxima verossimilhança restrita livre de derivada, por meio de modelos animais unicaracterística, com uso do aplicativo Multiple Traits Derivative-Free Restrict Maximum Likelihood (Boldman et al., 1995). Para P205, foi utilizado o modelo que inclui os efeitos aleatórios genéticos aditivos (direto e materno), efeitos de ambiente permanente materno, a covariável idade da vaca ao parto (efeitos linear e quadrático), além do efeito fixo de grupo de contemporâneos (GC), tendo-se admitido a covariância entre os efeitos genéticos direto e materno como nula. Para P365, foram considerados o mesmo efeito fixo e covariável, porém, apenas o efeito genético aditivo direto foi considerado como aleatório.

Os GC constituíram-se de animais do mesmo sexo, época (estação e ano de nascimento), fazenda e regime alimentar. Grupos de contemporâneos com menos de três animais foram excluídos das análises.

As estimativas das tendências genéticas, fenotípicas e ambientais das características foram obtidas pela regressão linear ponderada da média da variável dependente (valores genéticos, massas corporais observadas e soluções dos efeitos ambientais) sobre o ano de nascimento, por meio do SAS (SAS Institute, 1999).

Foi utilizada a regressão não paramétrica por meio de polinômios articulados ("spline") para descrever as tendências observadas nos gráficos. O estimador "spline" tem a forma

$\mathrm{S}(\lambda)=\frac{1}{3} \sum_{\mathrm{i}=1}^{\mathrm{n}}\left(\mathrm{y}_{\mathrm{i}}-\hat{\mathrm{f}}_{\lambda}(\mathrm{x})\right)^{2}+\lambda \int_{-\infty}^{\infty}\left(\hat{\mathrm{f}}_{\lambda}(\mathrm{x})\right)^{2} \mathrm{dx}$

em que: $S(\lambda)$ é o estimador de alisamento "spline", que ajusta um polinômio cúbico a cada intervalo entre pontos; $\hat{f}$ pertence ao conjunto das funções continuamente diferenciadas, com derivadas de segunda ordem de integráveis quadradas; $\lambda$ é uma constante positiva. $\mathrm{O} \lambda$ é o parâmetro de alisamento que controla a troca entre a bondade e o alisamento do ajuste. Um parâmetro de alisamento $\lambda$ é selecionado por especificar uma constante c na fórmula $\lambda-(Q / 10) 3 c$, em que $\mathrm{Q}$ é o intervalo interquartílico. Esta fórmula faz com que c seja independente da unidade de $\mathrm{x}$.

O programa Endog (Gutiérrez \& Goyache, 2005) foi utilizado para a análise do pedigree e estimação 
dos parâmetros baseados na probabilidade de origem do gene, tamanho efetivo e intervalo de gerações. O tamanho efetivo da população $(\mathrm{Ne})$ foi estimado por ano, conforme a equação seguir: $\mathrm{Ne}=(4 \mathrm{Nm} \times \mathrm{Nf}) /(\mathrm{Nm}+\mathrm{Nf})$, em que $\mathrm{Nm}$ é número de machos usados na reprodução e Nf é número de fêmeas usadas na reprodução.

O número efetivo de fundadores representa o número de animais com igual contribuição na fundação que produziria a mesma variabilidade genética encontrada na população estudada. O número efetivo de ancestrais representa o número mínimo de animais (fundadores ou não) necessário para explicar a diversidade genética total da população estudada (Gutiérrez \& Goyache, 2005).

A estatística $F_{\text {is }}$ de Wright (1938), que expressa o desvio da casualidade obtido nos acasalamentos atuais, foi calculada por meio do programa Endog (Gutiérrez \& Goyache, 2005). Para $\mathrm{F}_{\text {is }}$ maior que zero, considerou-se que a endogamia real ultrapassa o nível esperado de acasalamentos ao acaso. Isso implica que os acasalamentos estão acontecendo entre animais mais aparentados que a média e, consequentemente, que a população estará dividida em subpopulações. Para $\mathrm{F}_{\text {is }}$ menor que zero, considerou-se que a endogamia foi evitada ou que predominou o acasalamento entre subpopulações.

\section{Resultados e Discussão}

As médias e os desvios-padrão para P205 e P365 foram de 163,8 29,74 e $244,1 \pm 54,9 \mathrm{~kg}$, respectivamente. Malhado et al. (2008), ao estudar bovinos registrados da raça Nelore no Estado da Bahia, relataram médias de $167,0 \pm 34,5$ e $225,9 \pm 49,5 \mathrm{~kg}$ para P205 e P365, respectivamente.

Nos últimos cinco anos houve uma redução drástica do número de zebuínos registrados no Sertão, fato que reduziu também o número de nascimento de animais Nelore e o tamanho efetivo da raça na região (Figura 1). No início da década de 1980, também foi observada redução nesses números, provavelmente em razão da grande seca que assolou o Nordeste brasileiro no período 1979 a 1983, a maior dos últimos 40 anos (Arruda \& Sugai, 1994).

O maior número de nascimentos da raça Nelore ocorreu na década de 1990, período com maior número de matrizes e de maior tamanho efetivo (Figura 1).
É importante destacar que o período de 1993 a 1998 foi o de maior valor genético médio anual para a massa aos 205 dias de idade (Figura $2 \mathrm{~A}$ ).

O tamanho efetivo oscilou de 100 a 200 em quase todo o período estudado (Figura 1). Frankham (1995) sugere a adoção de um tamanho efetivo da ordem de 500 animais para manutenção do potencial evolutivo. Contudo, esse autor ressalta que, para a prevenção de depressão endogâmica, o tamanho efetivo de 50 animais é suficiente.

Os coeficientes de herdabilidade (efeito genético direto) foram $0,11 \pm 0,04$ e $0,10 \pm 0,06$ para P205 e P365, respectivamente (Tabela 1). Malhado et al. (2008) relataram coeficientes de herdabilidade na raça Nelore de 0,16 $\pm 0,02$ e 0,24 $\pm 0,02$ para P205 e P365, respectivamente. Lôbo et al. (2000), com base em 78 trabalhos sobre bovinos nos trópicos, observaram herdabilidade média de 0,30 e 0,37 para o efeito direto de P205 e P365, respectivamente. Lira et al. (2008), em 67 trabalhos com zebuínos, encontraram estimativas médias de herdabilidade direta de 0,28 e 0,31 para P205 e P365, respectivamente.

O coeficiente de herdabilidade genética materna para P205 foi $0,09 \pm 0,08$. Lira et al. (2008) relataram média de 0,12 para a mesma característica. Malhado et al. (2008) estimaram coeficiente de herdabilidade materna de 0,06 para $\mathrm{P} 205$.

Os valores dos coeficientes de herdabilidade direta para as duas características foram menores que os observados em literatura para outras raças zebuínas, o que indica menor variabilidade genética aditiva direta para o rebanho Nelore PO no Sertão Nordestino.

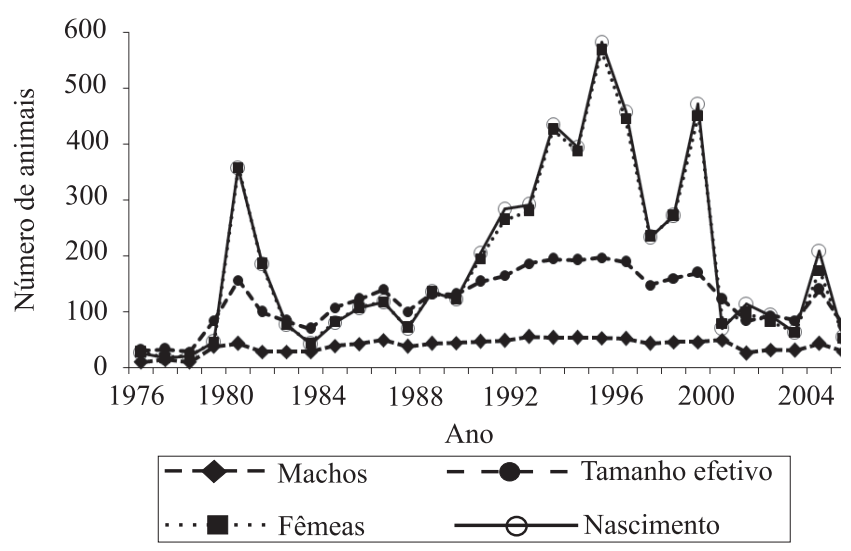

Figura 1. Número de animais nascidos, de reprodutores (machos e fềmeas) e tamanho efetivo da população (Ne) por ano, em rebanho Nelore Puro de Origem no Sertão Nordestino. 
Essas estimativas evidenciam menor oportunidade de ganho genético com a seleção para massa corporal nesses rebanhos. O coeficiente de herdabilidade materna para P205 foi baixo, e o erro-padrão dessa estimativa foi alto, o que reduz a confiabilidade na sua utilização.

As estimativas do intervalo de gerações para as quatro passagens gaméticas foram 9,2 $\pm 5,3$ (pai-filho), 8,8 $\pm 5,9$ (pai-filha), 8,7 $\pm 4,2$ (mãe-filho), $8,6 \pm 8,9$ anos (mãe-filha). O intervalo de gerações médio foi de $8,7 \pm 7,5$ anos. Os valores para as passagens gaméticas pai-filho e pai-filha são próximos aos relatados por Malhado et al. (2008) na raça Nelore e relativamente maiores que os relatados por Faria et al. (2002) e Vercesi Filho et al. (2002), que estimaram médias de 7,2 e 7,1 (pai-filho), 7,2 e 7,2 (pai-filha), 7,0 e 7,2 (mãe-filho) e 6,9 e 7,1 (mãe-filha), para animais registrados das raças Tabapuã e Nelore Mocho, respectivamente.
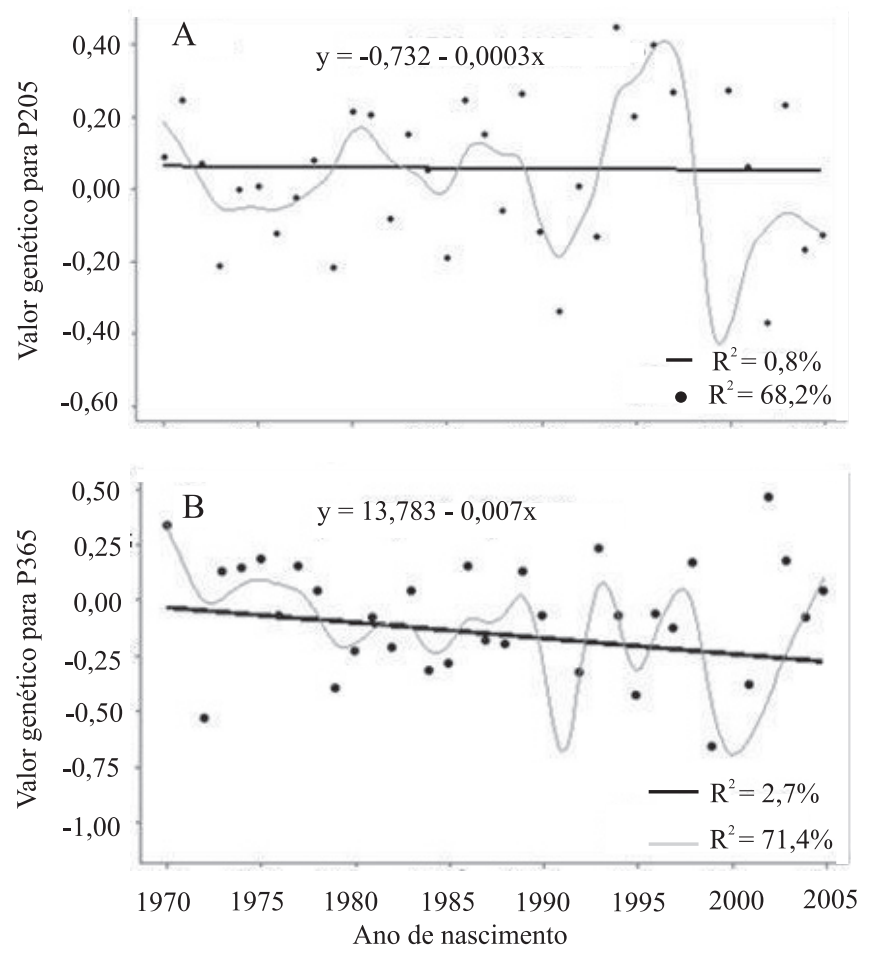

As tendências genéticas (regressão linear) do efeito genético direto não foram significativas ( $\mathrm{p}>0,05)$ para P205 e P365 (Figura 2), o que indica que não houve alteração nos valores genéticos dos animais durante o período avaliado, para as duas características. A tendência genética materna (regressão linear) para P205 também não foi significativa $(\mathrm{p}>0,05)$.

Em concordância com esses resultados, Biffani et al. (1999) frisaram que, nas condições de criação típicas do Nordeste, os animais são selecionados pelos criadores mais em razão das características anatômicas e raciais que do desempenho produtivo. Entretanto, essa tendência vem diminuindo nos últimos anos em algumas regiões do Nordeste, conforme podese verificar no estudo de Malhado et al. (2008), que relataram existência de pequeno ganho genético no desenvolvimento ponderal de bovinos da raça Nelore no Estado da Bahia, especialmente a partir de 1994.
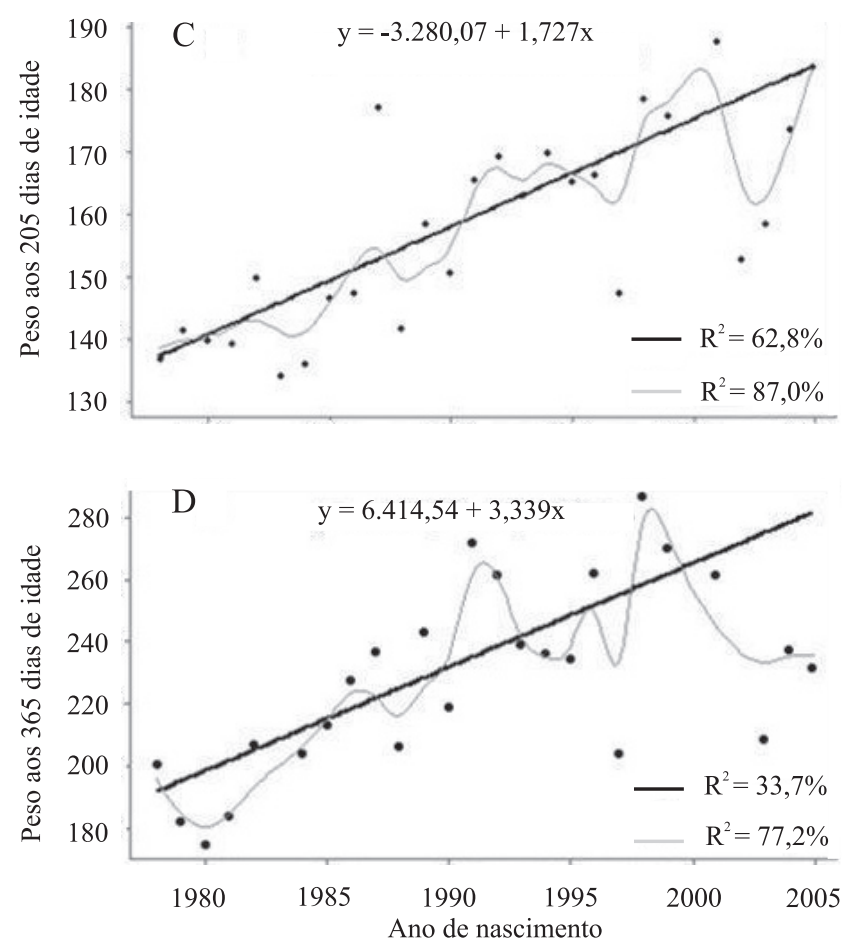

Figura 2. Tendência genética para o efeito direto das características P205 (A) e P365 (B) e tendência fenotípica para P205 (C) e P365 (D) em bovinos da raça Nelore no Sertão Nordestino.

Tabela 1. Estimativas dos componentes de variância e herdabilidade relativas às massas corporais aos 205 (P205) e 365 (P365) dias de idade em bovinos da raça Nelore no Sertão Nordestino brasileiro ${ }^{(1)}$.

\begin{tabular}{lccccccc}
\hline Massas corporais ajustadas & $\sigma_{\mathrm{a}}{ }^{2}$ & $\sigma_{\mathrm{m}}{ }^{2}$ & $\sigma_{\mathrm{ep}}{ }^{2}$ & $\sigma_{\mathrm{e}}{ }^{2}$ & $\sigma_{\mathrm{p}}{ }^{2}$ & $\mathrm{~h}_{\mathrm{d}}{ }^{2}$ & $\mathrm{~h}_{\mathrm{m}}{ }^{2}$ \\
\hline P205 & 43,31 & 36,99 & 77,02 & 244,28 & 401,63 & $0,11 \pm 0,04$ & $0,09 \pm 0,08$ \\
P365 & 76,63 & - & - & 673,35 & 749,99 & $0,10 \pm 0,06$ & - \\
\hline
\end{tabular}

${ }^{(1)} \sigma_{\mathrm{a}}{ }^{2}$, componente de variância genética aditiva direta; $\sigma_{\mathrm{m}}{ }^{2}$, componente de variância genética aditiva materna; $\sigma_{\mathrm{ep}}{ }^{2}$, variância de ambiente permanente materno; $\sigma_{\mathrm{e}}^{2}$, variância residual; $\sigma_{\mathrm{p}}{ }^{2}$, variância fenotípica; $\mathrm{h}_{\mathrm{d}}{ }^{2}$, herdabilidade direta; $\mathrm{h}_{\mathrm{m}}{ }^{2}$, herdabilidade materna. 
As tendências fenotípicas (regressão linear) para P205 e P365 foram significativas $(p<0,01)$ e iguais a 1,73 e $3,34 \mathrm{~kg}$ por ano, respectivamente. Esse progresso é atribuído principalmente ao ambiente, visto que a contribuição genética foi nula. As menores médias para as duas características ocorreram no início da década de 1980 (Figura 2), época marcada pela mais prolongada e abrangente seca da história do Nordeste. Outras grandes secas na região ocorreram nos anos de 1993 e 2001 e também resultaram em quedas nas massas corporais dos animais.

Corroborando os resultados de ganho fenotípico anual, as tendências ambientais foram significativas $(\mathrm{p}<0,01)$ e da ordem de 1,69 e 3,29 $\mathrm{kg}$ por ano para P205 e P365, respectivamente. Pode-se constatar, portanto, que apesar das peculiaridades do Sertão, que em âmbito geral são responsáveis por deficiências nutricionais, os produtores melhoraram ano após ano as condições de criação desses animais e obtiveram um considerável ganho ambiental e fenotípico. Entretanto, deve ser destacado um importante efeito de município, visto que aproximadamente $60 \%$ dos animais foram criados no Município de Antônio Almeida, no Estado do Piauí.

O coeficiente de endogamia médio e a percentagem de animais endogâmicos na população aumentaram no decorrer das gerações (Tabela 2). O simples fato de serem conhecidas mais gerações completas de um indivíduo aumenta a possibilidade de um ancestral importante aparecer diversas vezes no pedigree, o que justifica o aumento da percentagem de indivíduos endogâmicos com o decorrer das gerações. Entretanto, o coeficiente de endogamia médio dos animais endogâmicos diminuiu no decorrer das gerações, o que indica que os acasalamentos entre parentes próximos têm sido evitados.

A população referência, em que ambos os pais são conhecidos, continha 5.700 bovinos, sendo que 3.516 animais apresentavam um ou ambos os pais

Tabela 2. Coeficiente de endogamia médio (F), percentagem de indivíduos endogâmicos (\%End) e coeficiente de endogamia médio dos endogâmicos $\left(\mathrm{F}_{\text {end }}\right)$ em bovinos da raça Nelore, no Sertão Nordestino.

\begin{tabular}{cccc}
\hline Geração & $\mathrm{F}(\%)$ & $\%$ End & $\mathrm{F}_{\text {end }}(\%)$ \\
\hline 1 & 0,00 & - & - \\
2 & 0,06 & 0,32 & 20,0 \\
3 & 0,05 & 0,40 & 12,5 \\
4 & 0,22 & 4,17 & 5,2 \\
\hline
\end{tabular}

desconhecidos. O número efetivo de fundadores $\left(\mathrm{f}_{\mathrm{e}}\right)$ foi equivalente a 309 , e o incremento esperado de endogamia causado pela contribuição desbalanceada dos fundadores foi de $0,07 \%$. A contribuição genética dos 10, 30 e 167 ancestrais (fundadores ou não) mais influentes explicou, na mesma ordem, 12,5, 25,7 e 50\% da variabilidade genética de toda a população.

Os resultados indicam menor variabilidade genética que os relatados por Malhado et al. (2008) na raça Nelore, no Estado da Bahia. Esses autores descreveram que $50 \%$ da variabilidade genética da população foi explicada por 414 ancestrais, número 2,5 vezes maior ao encontrado no presente trabalho. $\mathrm{O}$ menor número de ancestrais explicando a variabilidade genética refletiu-se nos valores das variâncias genéticas, que foram aproximadamente 30 e $60 \%$ inferiores às relatadas por Malhado et al. (2008) para P205 e P365, respectivamente, e possivelmente pode explicar de forma parcial a tendência genética nula.

A estatística $\mathrm{F}_{\text {is }}$ de Wright (1938), que mede o desvio da casualidade nos acasalamentos, foi negativa, próxima a zero $(-0,0093)$ e revelou um pequeno predomínio de acasalamentos entre subpopulações, o que contribuiu para minimizar a endogamia. De acordo com Malhado et al. (2008), o valor negativo de $\mathrm{F}_{\text {is }}$ provavelmente está associado à utilização de inseminação artificial e ao intercâmbio de reprodutores, práticas importantes para o melhoramento genético da raça e a conectabilidade entre os rebanhos.

\section{Conclusões}

1. O reduzido número de ancestrais da população de Nelores Puros de Origem no Sertão Nordestino resulta na baixa variabilidade genética observada para as características de crescimento.

2. O considerável ganho fenotípico observado no período foi ocasionado exclusivamente por melhorias ambientais.

\section{Agradecimentos}

À Universidade Estadual do Sudoeste da Bahia e à Fundação de Amparo à Pesquisa do Estado da Bahia, pelo apoio financeiro; ao Conselho Nacional de Desenvolvimento Científico e Tecnológico, pela bolsa concedida ao primeiro autor, e à Associação Brasileira de Criadores de Zebu, pela cessão dos dados. 


\section{Referências}

ARRUDA, Z.J. de; SUGAI, Y. Regionalização da pecuária bovina no Brasil. Campo Grande: Embrapa-CNPGC; Brasília: Embrapa-SPI, 1994. 144p. (Embrapa-CNPGC. Documentos, 58).

BIFFANI, S.; MARTINS FILHO, R.; GIORGETTI, A.; BOZZI, R.; LIMA, F.A.M. Fatores ambientais e genéticos sobre o crescimento ao ano e ao sobreano de bovinos Nelore, criados no Nordeste do Brasil. Revista Brasileira de Zootecnia, v.28, p.468-473, 1999.

BOLDMAN, K.G.; KRIESE, L.A.; VAN VLECK, L.D.; VAN TASSEL, C.P.V.; KACHMAN, S.D. A manual for use of MTDFREML: a set of programs to obtain estimates of variances and covariances [DRAFT]. Lincoln: Agricultural Research Service, 1995. 120p.

EUCLIDES FILHO, K.; SILVA, L.O.C. da; ALVES, R.G. de O.; FIGUEIREDO, G.R. de. Tendência genética na raça Gir. Pesquisa Agropecuária Brasileira, v.35, p.787-791, 2000.

FARIA, F.J.C.; VERCESI FILHO, A.E.; MADALENA, F.E.; JOSAHKIAN, L.A. Estrutura populacional da raça Nelore Mocho. Arquivo Brasileiro de Medicina Veterinária e Zootecnia, v.54, p.501-509, 2002.

FRANKHAM, R. Conservation genetics. Annual Review of Genetics, v.29, p.305-327, 1995.

GUTIÉRREZ, J.P.; GOYACHE, F. A note on ENDOG: a computer program for analysing pedigree information. Journal of Animal Breeding and Genetics, v.122, p.172-176, 2005.

LIRA, T. de; ROSA, E.M.; GARNERO, A. del V. Parâmetros genéticos de características produtivas e reprodutivas em zebuínos de corte (revisão). Ciência Animal Brasileira, v.9, p.1-22, 2008.

LÔBO, R.N.B.; MADALENA, F.E.; VIEIRA, A.R. Average estimates of genetic parameters for beef and dairy cattle in tropical regions. Animal Breeding Abstracts, v.68, p.433-462, 2000.

MALHADO, C.H.M.; CARNEIRO, P.L.S.; PEREIRA, D.G.; MARTINS FILHO, R. Progresso genético e estrutura populacional do rebanho Nelore no Estado da Bahia. Pesquisa Agropecuária Brasileira, v.43, p.1163-1169, 2008.

SAS INSTITUTE. SAS: user guide. Versão 8. Cary: SAS Institute, 1999.

VALERA, M.; MOLINA, A.; GUTIÉRREZ, J.P.; GÓMEZ, J.; GOYACHE, F. Pedigree analysis in the Andalusian horse: population structure, genetic variability and influence of the Carthusian strain. Livestock Production Science, v.95, p.57-66, 2005.

VERCESI FILHO, A.E.; FARIA, F.J.C.; MADALENA, F.E.; JOSAHKIAN, L.A. Estrutura populacional do rebanho Tabapuã registrado no Brasil. Arquivo Brasileiro de Medicina Veterinária e Zootecnia, v.54, p.609-617, 2002.

$\overline{\text { Recebido em } 19 \text { de fevereiro de } 2009 \text { e aprovado em } 22 \text { de junho de } 2009}$ 